\title{
Motion Control Systems with Network Delay
}

UDK 681.518 .23

IFAC 4.5.6; 5.8.6

Original scientific paper

\begin{abstract}
In this paper motion control systems with delay in measurement and control channels are discussed and a new structure of the observer-predictor is proposed. The feature of the proposed system is enforcement of the convergence in both the estimation and prediction of the plant output in the presence of the variable, unknown delay in both measurement and in control channels. The estimation is based on the available data - undelayed control input, the delayed measurement of position or velocity and the nominal parameters of the plant - and does not require apriori knowledge of the delay. The stability and convergence is proven and selection of observer and the controller parameters are discussed. Experimental results are shown to illustrate the theoretical predictions.
\end{abstract}

Key words: Motion control, Network time delay, Observers, Disturbance observer

Sustavi upravljanja gibanjem s komunikacijskim kašnjenjem. U ovom je radu razmotren sustav upravljanja gibanjem uz prisutno kašnjenje u mjernom i upravljačkom komunikacijskom kanalu te su predložene nove strukture estimacije/predikcije iznosa kašnjenja. Svojstvo predloženog sustava je poboljšanje konvergencije estimacije/predikcije izlaza iz procesa u prisustvu promjenjivog i nepoznatog kašnjenja u mjernom i upravljačkom kanalu. Estimacija se zasniva na dostupnim podacima - upravljačkom signalu bez kašnjenja, mjerenim signalima položaja ili brzine te nazivnim parametrima procesa- i ne zahtjeva a-priori poznavanje iznosa kašnjenja. Dokazana je stabilnosti i konvergencija sustava upravljanja. Odabran je estimator, a definirani su i parametri regulatora. Prikazani su eksperimentalni rezultati kojima se ilustrira valjanost teoretskih rezultata.

Ključne riječi: upravljanje gibanjem, mrežno kašnjenje, estimator, estimator poremećaja

\section{INTRODUCTION}

Control of systems with delay in measurement and/or in control channel, due to the wide use of the network and teleoperation, is becoming very interesting research topic. Such systems are encountered in remotely controlled structures. Ideal bilateral control allows extension of a person's sensing to a remote environment. It has been paid considerable attention in the recent and is expected to be an emerging point of modern developments in robotics, micro-parts handling, control theory and virtual reality systems. The potential applications of the teleoperation include network robotics, tele-surgery, space and seabed tele-manipulation, micro-nano parts handling, inspection and assembly. In recent years many interesting solutions ranging from variation of the classic Smith Predictor [1-3] to control based on sliding modes [4] and $\mu$-Synthesis [5] is developed. Oboe and Fiorini proposed a design strategy of internet-based tele-robotics [6]. Uchimura and Yokoh described bilateral robot system on hard real time networks [7]. Passivity based approaches like scattering theory and wave variables have predominated the research field [8-10]. Those approaches assure the passivity as well as stability and are valid for constant delay. However, those are not able to be directly applied to time-varying delay cases. Among the proposed methods, the Communication Disturbance Observer (CDOB) based control of systems with delay [11] stands on its own as a simple design procedure based on well known disturbance observer method. It offers a framework for the application of the disturbance observer for the systems with constant and/or time varying delay. Experimental results has confirmed applicability but at the same time revealed problem related to the convergence of the estimated-predicted value to the plant's output, especially in the case of time varying delay.

In this paper, problems in control of motion systems with time delay in both measurement and the control channels will be discussed. The solution will be proposed in the general framework of disturbance observer method with additional compensation selected to guaranty the convergence of the estimated plant variables in the presence of unknown possibly time varying time delay in both measurement and control channels. These additional compensation terms are shown to be essential improvement of the CDOB, guarantying the convergence and stability. 
The paper is organized as follows. In section 2, the plant and the problem statement are given. In section 3 , the solution for systems with time delay and the dynamic distortion in the measurement channel are discussed. In section 4 , the solution for the systems with delay in both measurement and control channels are presented. In section 5, the closed loop behavior and the experimental results of the system with time delay in both measurement and control channel are presented. And finally in section 6, extensions to bilateral control systems with delay in both channels are discussed.

\section{PLANT AND PROBLEM STATEMENT}

Assume known one DOF motion control system exposed to unknown time delay in control channel and unknown dynamics and delay in the measurement channel. The error in measurement may consist of time delay, dynamical distortion and nonlinear gain in any combination. Due to the fact that it appears in measurement channel it can be treated as a block in series with system output as depicted in Fig. 1. At the same time, the transmission of control signal is assumed to be distortion free except for the time delay.

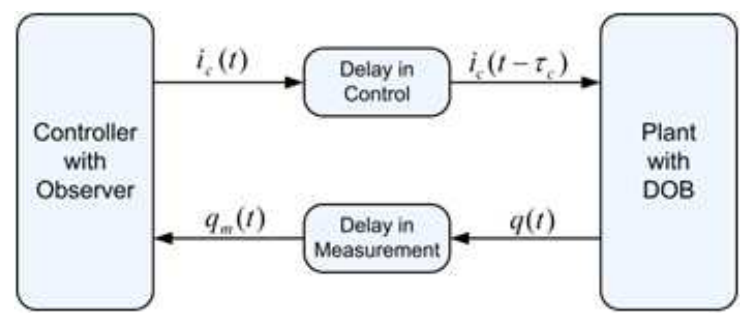

Fig. 1. Single DOF system with distortion and delay in measurement and control channels

The analysis and design will be demonstrated on a single DOF motion control system (1) for which the torque $\tau(t)=K_{n} i(t)$ is proportional to the current $i(t)$ and all uncertainties of the parameters and other forces acting on the system are lumped into the disturbance term $\tau_{\text {dis }}(t)$. This way the dynamics is described by

$$
a_{n} \dot{v}(t)=\tau(t)-\tau_{d i s}(t)
$$

where

$$
\begin{aligned}
v(t) & =\dot{q}(t), \\
\tau(t) & =K_{n} i(t), \\
\tau_{\text {dis }}(t) & =\left(a-a_{n}\right) \dot{v}(t)+b(q, v)+g(q)+\tau_{\text {ext }}(t) .
\end{aligned}
$$

Nominal inertia and torque constant $a_{n}, K_{n}$ are assumed known. General acceleration control framework [11] for system (1) allows defining the control input in terms of the desired acceleration and consequently input current may be expressed as

$K_{n} i(t)=a_{n} \dot{v}^{d e s}(t)+\widehat{\tau}_{d i s}(t)=K_{n} i_{v}(t)+K_{n} \widehat{\dot{i}}_{d i s}(t)$.

Component $K_{n} i_{v}(t)$ corresponds to the desired motion of the system $K_{n} i_{v}(t)=a_{n} \ddot{q}^{\text {des }}(t)$ and component $\widehat{\tau}_{\text {dis }}(t)=K_{n} \widehat{\dot{i}}_{\text {dis }}(t)$ corresponds to the disturbance compensation.

In this paper, the restoration of the system coordinates in the presence of network delay in the system and design of the network controller will be discussed. Nominal parameters of the plant are assumed known and measurements are subject only to network non idealities (delay and dynamic distortions) while control is subject to network delay. The goal is to design controller based on available data such that stability of the closed loop system is guaranteed and at least delay and nonlinearity in measurement channel is compensated while delay in control channel may result in delay in output.

\section{NONLINEARITY AND DELAY IN MEASURE- MENT CHANNEL}

Further the output of the real plant at time $t$ will be labeled as $q(t)$ and $\mathrm{v}(t)$. For systems with delay in the control channel, the output of the "ideal plant" without delay in the control channel will be labeled as $q_{t}(t)$ and $v_{t}(t)$. For plant without delay in the control channel these two sets of variables are equal, thus $q(t)=q_{t}(t)$ and $v(t)=v_{t}(t)$ is valid. In system under consideration, controller current component $i_{c}(t)$ is sent to the plant and the disturbance observer is applied, so motion of the plant is driven by $K_{n} i(t)=K_{n} i_{c}(t)+K_{n} i_{o b}(t)$. Since component $i_{c}(t)$ is originating on the plant side, it is not subject to the delay in the control channel. Note that $i_{o b}(t)$ can be selected to compensate part of disturbance thus it allows flexibility in selecting compensation strategy at plant side. The disturbance observer is assumed to enforce the nominal parameters of the system.

The measurements available at controller side are described as

$$
\begin{aligned}
& q_{m}(t)=q\left(t-T_{m}\right)=q\left(t, T_{m}\right), \\
& v_{m}(t)=v\left(t-T_{m}\right)=v\left(t, T_{m}\right),
\end{aligned}
$$

where $T_{m}$ stands for unknown, possibly varying time delay in the measurement channel. The distortions in both position and velocity measurements are assumed the same and both signals $q_{m}(t)$ and $v_{m}(t)$ are assumed available. In order to avoid long expressions, a shorthand notation $x\left(t-T_{m}\right)=x\left(t, T_{m}\right)$ will be used from now on. The time " $\mathrm{t}$ " is referred to the time at controller side. Index " $\mathrm{m} "$ will be used to mark measurements. Since there is no delay 
in the control channel, input $K_{n} i_{c}(t)$ is transferred to the plant without delay. Available measurements dictate observer design based on plant nominal model and enforcement of tracking both or only one of the measured values of $q_{m}(t)$ and $v_{m}(t)$.

Let us first analyze velocity tracking observer as in

$$
a_{n} \dot{z}(t)=K_{n} i_{c}(t)-u_{z}\left(\varepsilon_{z}(t)\right),
$$

with error defined by $\varepsilon_{z}(t)=v_{m}(t)-z(t)$. Control $u_{z}\left(\varepsilon_{z}(t)\right)$ in (3) forces the output $z(t)$ of the nominal plant with parameters $a_{n}, K_{n}$ and input $K_{n} i_{c}(t)$, to track the measured signal $v_{m}(t)$. Assume control $u_{z}\left(\varepsilon_{z}(t)\right)$ is selected in such a way that finite time convergence of error $\varepsilon_{z}(t)=0$ is enforced (for example sliding mode is enforced by control $u_{z}\left(\varepsilon_{z}(t)\right)=-k \varepsilon_{z}-\mu \operatorname{sign}\left(\varepsilon_{z}\right)$ with $k>0$ and $\mu$ being small positive constant that ensures finite time convergence in manifold $\left.\varepsilon_{z}(t)=0\right)$. Then equivalent control $u_{z e q}\left(\varepsilon_{z}(t)\right)$ maintaining motion in manifold $\left.\varepsilon_{z}(t)\right|_{t>t_{0}}=0$ with initial conditions $\varepsilon_{z}\left(t_{0}\right)$ can be determined as

$$
\varepsilon_{z}(t)=\dot{v}_{m}(t)-\dot{z}(t),
$$

where

$$
\begin{aligned}
\dot{z}(t) & =\frac{K_{n} i_{c}(t)-u_{z e q}\left(\varepsilon_{z}\right)}{a_{n}}, \\
u_{z e q}\left(\varepsilon_{z}\right) & =K_{n} i_{c}(t)-a_{n} \dot{v}_{m}(t) .
\end{aligned}
$$

Assuming that input to the plant (1) from controller side is the same as input to the observer (i.e. $K_{n} i(t)=K_{n} i_{c}(t)$ ), by solving equation in (1) for $K_{n} i_{c}(t)$, and plugging $K_{n} i_{c}(t)=a_{n} \dot{v}(t)+\tau_{\text {dis }}(t)$ into (4), the equivalent control $u_{z e q}\left(\varepsilon_{z}\right)$ may be expressed as

$$
u_{z e q}\left(\varepsilon_{z}\right)=\tau_{d i s}(t)-a_{n}\left(\dot{v}_{m}(t)-\dot{v}(t)\right) .
$$

Control $u_{z e q}\left(\varepsilon_{z}\right)$ represents difference between weighted acceleration of nominal and virtual plant, that with input $K_{n} i_{c}(t)$, will have output $v_{m}(t)$. From (4), one can derive

$$
a_{n}\left(\dot{v}(t)-\dot{v}_{m}(t)\right)+\tau_{d i s}(t)=u_{z e q}\left(\varepsilon_{z}\right) .
$$

Now the observer estimating the velocity and position of the plant may be expressed from (5) in the form

$$
a_{n} \widehat{\dot{v}}(t)=u_{z e q}\left(\varepsilon_{z}\right)+a_{n} \dot{v}_{m}(t)-\tau_{d i s}(t),
$$

where

$$
\begin{aligned}
\widehat{\dot{v}}(t) & =\widehat{\ddot{q}}(t), \\
\varepsilon_{z}(t) & =v_{m}(t)-z(t), \\
a_{n} \dot{z}(t) & =K_{n} i_{c}(t)-u_{z}\left(\varepsilon_{z}(t)\right) .
\end{aligned}
$$

In order to estimate plant velocity, one has to know $\tau_{d i s}$. If disturbance is compensated on the plant directly and estimation error is expressed as $\tau_{d i s}-\widehat{\tau}_{d i s}=p_{1}\left(\tau_{d i s}\right)$ then
(5) may be expressed as $a_{n}\left(\dot{v}(t)-\dot{v}_{m}(t)\right)+p_{1}\left(\tau_{d i s}\right)=$ $u_{z e q}\left(\varepsilon_{z}\right)$ and consequently estimation of the plant dynamics can be expressed as

$$
a_{n} \widehat{\dot{v}}(t)=a_{n} \dot{v}_{m}(t)+u_{z e q}\left(\varepsilon_{z}(t)\right)-p_{1}\left(\tau_{d i s}\right),
$$

with $\hat{v}(t)=\widehat{\dot{q}}(t)$. Estimation error depends on the initial conditions in plant and the observer. Additional error in (7) is given by $\int p\left(\tau_{d i s}\right) d \xi$ and is determined by the accuracy of the disturbance compensation on the plant side. Dependence on the uncompensated plant disturbance may be used to insert convergence term in otherwise open loop integration in (7). In order to introduce the convergence term into observer, assume that uncompensated disturbance term is $\left(K_{D} v(t)+K_{P} q(t)\right)$ and that observer (3) is modified as

$$
a_{n} \dot{z}(t)=K_{n} i_{c}(t)-K_{D} \hat{v}(t)-K_{P} \hat{q}(t)-u_{z}\left(\varepsilon_{z}(t)\right),
$$

with error being $\varepsilon_{z}(t)=v_{m}(t)-z(t)$.

The plant dynamics with uncompensated term $\left(K_{D} v(t)+K_{P} q(t)\right)$ and with input $K_{n} i_{c}(t)$ may be written as

$$
a_{n} \dot{v}(t)=K_{n} i_{c}(t)-K_{D} v(t)-K_{P} q(t)-p_{1}\left(\tau_{d i s}\right),
$$

where $v(t)=\dot{q}(t)$. Here $p\left(\tau_{\text {dis }}\right)$ stands for the remaining disturbance compensation error. From tracking conditions in the observer (8), equivalent control may be expressed as $u_{z e q}\left(\varepsilon_{z}(t)\right)=K_{n} i_{c}(t)-K_{D} \hat{v}(t)-K_{P} \hat{q}(t)-a_{n} \dot{v}_{m}(t)$.

The plant velocity observer may now be expressed in the form

$$
a_{n} \widehat{\dot{v}}(t)=a_{n} \dot{v}_{m}(t)+u_{z e q}\left(\varepsilon_{z}(t)\right) .
$$

From (9), (10) and (11), the estimation error can be expressed as

$$
a_{n} \Delta \ddot{q}(t)+K_{D} \Delta \dot{q}(t)+K_{P} \Delta \mathrm{q}(\mathrm{t})=-p_{1}\left(\tau_{d i s}\right) \cong 0 .
$$

The observer error depends on the composition of the disturbance. Under the conditions that $p_{1}\left(\tau_{d i s}\right)=0$, the estimation error will converge to zero if the convergence gains are strictly positive (i.e. $K_{D}, K_{P}>0$ ). The term $K_{D} v(t)+K_{P} q(t)$ should be inserted to the plant input and the rest of the system disturbances should be compensated by plant disturbance observer. The estimated value evaluates the plant output at current time from the current value of the control input and the delayed measurement of the plant output. In a sense it plays a dual role of estimation and prediction of the plant output. The error is defined by the accuracy of the compensation in the variation of plant parameters and external interaction forces. The convergence of the estimated-predicted value to the real one depends on the stability of the plant parameters $K_{D}$ and $K_{P}$. The structure of the observer is shown in Fig. 2 . 


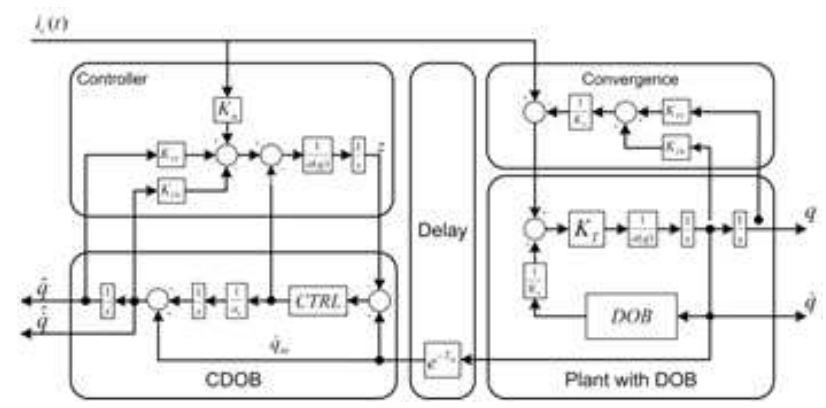

Fig. 2. Structure of the disturbance observer without delay in the control channel

\section{DELAY IN MEASUREMENT AND CONTROL CHANNELS}

A single DOF motion control system (1) in the presence of the delay $T_{c}$ in the control channel may be described as

$$
a_{n} \dot{v}(t)=K_{n} i_{c}\left(t-T_{c}\right)-\tau_{d i s}(t),
$$

where $v(t)=\dot{q}(t)$.

As a reference, time $t$ at which the control signal $K_{n} i_{c}(t)$ is generated and entered to the control communication channel, will be taken. With such reference for the time, the plant outputs that correspond to the input $K_{n} i_{c}(t)$ will be labeled as $q_{t}(t)$ and $v_{t}(t)$ and can be expressed as

$$
a_{n} \dot{v}_{t}(t)=K_{n} i_{c}(t)-\tau_{d i s}(t)
$$

where $v_{t}(t)=\dot{q}_{t}(t)$. The measurements available at the controller side may be defined as

$q_{m}(t)=q\left(t-T_{m}\right)=q_{t}\left(t-T_{c}-T_{m}\right)=q_{t}\left(t, T_{c}, T_{m}\right)$, $v_{m}(t)=v\left(t-T_{m}\right)=v_{t}\left(t-T_{c}-T_{m}\right)=v_{t}\left(t, T_{c}, T_{m}\right)$.

In order to avoid long expressions, a shorthand notation $x\left(t-T_{m}\right)=x\left(t, T_{m}\right)$ and $x\left(t-T_{c}-T_{m}\right)=$ $x\left(t, T_{c}, T_{m}\right)$ will be used from now on. The goal is to design a control system based on available measurements $q_{m}(t)$ and $v_{m}(t)$, the control input $K_{n} i_{c}(t)$ and the nominal parameters of the plant that will guarantee stable tracking of the reference. The response of the plant may have time delay equal to the control channel time delay.

Let us first construct the control forcing nominal plant with input $K_{n} i_{c}(t)$ to track the measured output $v_{m}(t)$ of the real plant as defined in

$$
a_{n} \dot{z}(t)=K_{n} i_{c}(t)-u_{z}\left(\varepsilon_{z}(t)\right),
$$

where $\varepsilon_{z}(t)=v_{m}(t)-z(t)$. Inserting acceleration from (1) into the expression for equivalent control yields

$$
u_{z e q}\left(\varepsilon_{z}(t)\right)=a_{n} \dot{v}_{t}(t)-a_{n} \dot{v}_{m}(t)+\tau_{d i s}(t) .
$$

From (17), one can write the predicted plant output at time $t$ in the form

$$
a_{n} \widehat{\dot{v}}_{t}(t)=u_{z e q}\left(\varepsilon_{z}(t)\right)+a_{n} \dot{v}_{m}(t)-\tau_{d i s}(t),
$$

where $\widehat{\dot{v}}_{t}=\widehat{\ddot{q}}_{t}$.

The full compensation of disturbance on the plant would lead to an observer without convergence term similarly as the one given in (7). Let uncompensated disturbance term be $K_{D} v(t)+K_{P} q(t)$ and that observer (16) be modified as

$a_{n} \dot{z}(t)=K_{n} i_{c}(t)-K_{D} \hat{v}_{t}(t)-K_{P} \hat{q}_{t}(t)-u_{z}\left(\varepsilon_{z}(t)\right)$,

with error defined by $\varepsilon_{z}(t)=v_{m}(t)-z(t)$. The dynamics of the plant (13) with uncompensated term $K_{D} v(t)+$ $K_{D} q(t)$ and with input $K_{n} i_{c}(t)$ may be written as

$a_{n} \dot{v}_{t}(t)=K_{n} i_{c}(t)-K_{D} v_{t}(t)-K_{P} q_{t}(t)-p_{1}\left(Q_{d}, \tau_{d i s}\right)$.

Here $p_{1}\left(Q_{d}, \tau_{d i s}\right)$ stands for the remaining disturbance compensation error. From tracking conditions in the observer (19), equivalent control may be expressed as

$u_{z e q}\left(\varepsilon_{z}(t)\right)=K_{n} i_{c}(t)-K_{D} \hat{v}_{t}(t)-K_{P} \hat{q}_{t}(t)-a_{n} \dot{v}_{m}(t)$.

By deriving $K_{n} i_{c}(t)$ from equation (20) and inserting it into (21), one may obtain

$$
\begin{aligned}
& u_{z e q}\left(\varepsilon_{z}(t)\right)+a_{n} \dot{v}_{m}(t)=a_{n} \dot{v}_{t}(t)+K_{D}\left(v_{t}(t)-\hat{v}_{t}(t)\right)+ \\
& +K_{P}\left(q_{t}(t)-\hat{q}_{t}(t)\right)+p_{1}\left(Q_{d}, \tau_{d i s}\right) .
\end{aligned}
$$

In order to ensure convergence to zero of the estimation error $\Delta q(t)=q_{t}(t)-\hat{q}_{t}(t)$, the left hand side of (22) should be equal to $a_{n} \dot{v}_{t}(t)$, thus velocity observer should be

$$
a_{n} \widehat{\dot{v}}_{t}(t)=a_{n} \dot{v}_{m}(t)+u_{z e q}\left(\varepsilon_{z}(t)\right) \text {. }
$$

From (22) and (23), the estimation error may be expressed as

$a_{n} \Delta \ddot{q}_{t}(t)+K_{D} \Delta \dot{q}_{t}(t)+K_{P} \Delta q_{t}(t)=-p_{1}\left(Q_{d}, \tau_{d i s}\right)$,

where $\Delta q_{t}(t)=q_{t}(t)-\hat{q}_{t}(t)$. Under the conditions that $p_{1}\left(Q_{d}, \tau_{d i s}\right)=0$, the estimation error will converge to zero if the convergence gains are strictly positive (i.e. $\left.K_{D}, K_{P}>0\right)$.

The observer unites the function of the predictor and compensator for the dynamic distortion. It should be noted here that almost the same result can be obtained if instead of the equivalent control, the disturbance observer like structure is used. This follows from the nature of the information contained in the equivalent control - it is essentially the disturbance perceived as acting on the input 
of the nominal system without delays. Solution with disturbance observers is detailed in [11].

In the observer design, no assumptions on the nature of the delay in the sense of being constant or time varying or being equal or different in the control and measurement channels has been introduced. The elements determining the accuracy of the observer are related to the accuracy of the nominal parameters of the plant $a_{n}, K_{n}$ and the accuracy of the compensation of disturbance on the plant and the design parameters $K_{D}, K_{P}$. From the structure of the convergence (24), the estimation error follows that it actually depends on the nominal acceleration.

Essential part of the observer design is enforcing accurate calculation of the apparent disturbance perceived acting on the input of the system due to the time delays and distortions in the measurement and control channels. The usage of the finite time convergence and the equivalent control is not essential. It has advantage of making convergence dynamics simpler. Application of the disturbance observer would introduce additional fast dynamics and it should be carefully evaluated. Such structure may be easier to implement and if high bandwidth is obtained may offer an easier way of realizing the system.

\section{CLOSED LOOP BEHAVIOUR AND EXPERI- MENTAL RESULTS}

Analysis of the closed loop behavior assumes knowing structure of the controller that provides control signal $K_{n} i_{c}(t)$. In order to make analysis simpler, let controller be selected as PD with acceleration feed forward term:

$$
\begin{aligned}
& K_{n} i_{c}(t)=\ddot{q}^{r e f}(t)+K_{D C}\left(\dot{q}^{r e f}(t)-\hat{v}(t)\right)+ \\
& \quad+K_{P C}\left(q^{r e f}(t)-\hat{q}(t)\right) .
\end{aligned}
$$

The dynamics of the plant with delay in input channel is

$$
\begin{aligned}
& a_{n} \dot{v}(t)=K_{n} i_{c}\left(t-T_{c}\right)-K_{D} v(t)- \\
& \quad-K_{P} q(t)-p_{1}\left(Q_{d}, \tau_{d i s}\right) .
\end{aligned}
$$

By inserting control (25) into (26), the closed loop dynamics may be described as

$$
\begin{aligned}
& \ddot{q}(t)+K_{D} \dot{q}(t)+K_{P} q(t)+K_{D C} \hat{\dot{q}}\left(t, T_{c}\right)+K_{P C} \hat{q}\left(t, T_{c}\right)= \\
& =\ddot{q}^{r e f}\left(t, T_{c}\right)+K_{D C} \dot{q}^{r e f}\left(t, T_{c}\right)+K_{P C} q^{r e f}\left(t, T_{c}\right) .
\end{aligned}
$$

Having convergence of the estimated values defined by (24), one can write $\hat{q}(t)=q(t)+\xi$ and $\hat{v}(t)=v(t)+\xi$ with $\xi, \zeta \underset{t \rightarrow \infty}{\longrightarrow} 0$. This way, equation (27) can be written as

$$
\begin{aligned}
& \ddot{q}_{t}(t)+K_{D} \dot{q}(t)+K_{P} q(t)+K_{D C} \dot{q}\left(t, T_{c}\right)+K_{P C} q\left(t, T_{c}\right)= \\
& \ddot{q}^{r e f}\left(t, T_{c}\right)+K_{D C} \dot{q}^{r e f}\left(t, T_{c}\right)+K_{P C} q^{r e f}\left(t, T_{c}\right)+\varepsilon(\xi, \zeta) .
\end{aligned}
$$

In (28), $\varepsilon(\xi, \zeta) \underset{t \rightarrow \infty}{\longrightarrow} 0$ and consequently closed loop behaviour is described by

$$
\begin{aligned}
& \ddot{q}(t)+K_{D} \dot{q}(t)+K_{P} q(t)+K_{D C} \dot{q}\left(t, T_{c}\right)+K_{P C} q\left(t, T_{c}\right)= \\
& =\ddot{q}^{r e f}\left(t, T_{c}\right)+K_{D C} \dot{q}^{r e f}\left(t, T_{c}\right)+K_{P C} q^{r e f}\left(t, T_{c}\right)
\end{aligned}
$$

The expression in equation (29) may be rewritten as

$$
\begin{aligned}
& {\left[\begin{array}{c}
\dot{q}(t) \\
\dot{v}(t)
\end{array}\right]=\left[\begin{array}{cc}
0 & 1 \\
-K_{P} & -K_{D}
\end{array}\right]\left[\begin{array}{l}
q(t) \\
v(t)
\end{array}\right]+} \\
& +\left[\begin{array}{cc}
0 & 0 \\
-K_{P C} & -K_{D C}
\end{array}\right]\left[\begin{array}{l}
q\left(t, T_{c}\right) \\
v\left(t, T_{c}\right)
\end{array}\right]=\left[\begin{array}{c}
0 \\
\dot{v}^{\text {ref }}\left(t, T_{c}\right)
\end{array}\right]+ \\
& +\left[\begin{array}{cc}
0 & 0 \\
-K_{P C} & -K_{D C}
\end{array}\right]\left[\begin{array}{l}
q^{r e f}\left(t, T_{c}\right) \\
v^{r e f}\left(t, T_{c}\right)
\end{array}\right] .
\end{aligned}
$$

In [1] it has been shown that for system represented in the form

$$
\dot{\mathbf{x}}(t)=\mathbf{A}_{\mathbf{1}} \mathbf{x}(t)+\mathbf{A}_{\mathbf{2}} \mathbf{x}(t-\tau)
$$

the stability requires $\mathbf{A}_{\mathbf{1}}+\mathbf{A}_{\mathbf{2}}$ to be Hurwitz, and that there exists positive definite symmetric matrices $\mathbf{P}, \mathbf{S}, \mathbf{R}$ such that

$$
\mathbf{A}_{1}^{\mathbf{T}} \mathbf{P}+\mathbf{P A}_{1}+\mathbf{P A}_{2} \mathbf{S}^{-1} \mathbf{A}_{2}^{\mathbf{T}} \mathbf{P}+\mathbf{S}+\mathbf{R}=\mathbf{0} .
$$

Due to the fact that matrices $\mathbf{A}_{1}$ and $\mathbf{A}_{2}$ depend on the design parameters (the observer convergence gains and the controller gains) and not on the plant parameters, one may use this stability conditions to determine range of the design parameters for which stability for the closed loop system will be ensured for selected matrices $\mathbf{P}, \mathbf{S}, \mathbf{R}$. The robustness on the change of delay should be separately investigated. Structure of the closed loop control system with delay in both measurement and control channels is depicted in Fig. 3. Illustration of the closed loop system behavior is verified on an experimental system consisting of linear motors. Two Hitachi-ADA series linear

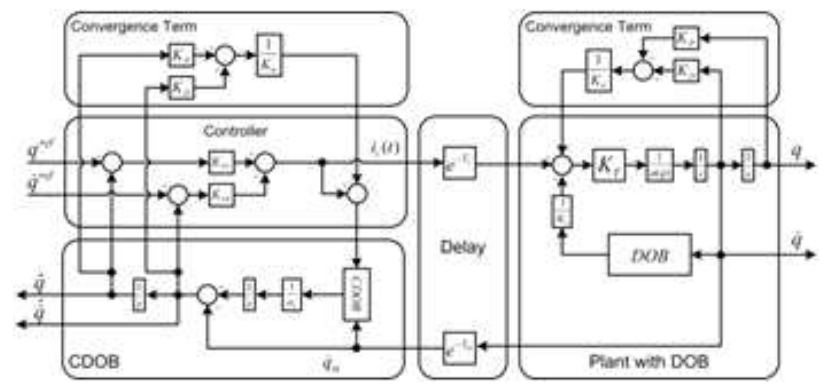

Fig. 3. Structure of the closed loop control system with delay in measurement and control channels 
AC motors and drivers were realized as experimental platform. The linear motors had incremental encoders with 1 $\mu \mathrm{m}$ resolution. MATLAB-Simulink environment was used as the implementation software and real time processing was enabled by a D-Space DS1103 card. A picture of the experimental setup is provided in Fig. 4.

The experiments are conducted with time delay in both measurement and control channels. To approximate the most realistic scenario, the structure of the time delay is adjusted to have variation within a certain range over a constant value. During the first set of experiments, one of the identical motors (the master system) were controlled under computer generated step and sine references while the position and velocity readout of this system were sent as input to the second motor (the slave system). Fig. 5 and Fig. 6 depict the first set of experiments for which a variable delay of $20 \mathrm{~ms}$ is added on top of a $500 \mathrm{~ms}$ constant delay both in measurement and control channels.

The controller gains for the given experiments were tuned to be $K_{P C}=980$ and $K_{D C}=2.1$ while the convergence gains were set to have the values $K_{P}=25$ and $K_{D}=8$. The filter in DOB is set to the value $g=1000$ while the filter in velocity has the value $g=200$.

In the second set of experiments, the input to the slave system was again created from the position and velocity measurement of the master system. However, in this second set, the input to the master system was not a computer generated reference. Instead, a human operator moved the master system with an arbitrary motion to see the closed loop behavior of the proposed controller under random references. The result of random motion experiment, depicted in Fig. 7. indicates a further realization of motion synchronization for master slave teleoperation systems operated under arbitrary network delay. The stability of the slave system was preserved during motion while a very satisfactory tracking is achieved. Experiments were conducted for

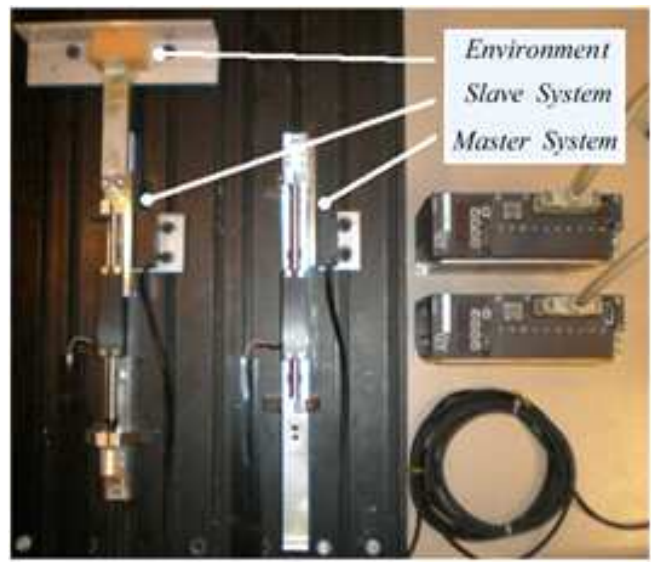

Fig. 4. Experimental Setup a variable time delay of $50 \mathrm{~ms}$ added to a constant delay of $500 \mathrm{~ms}$ both in measurement and control channels.

\section{EXTENSIONS TO BILATERAL SYSTEMS}

The proposed compensation of time delay can easily be incorporated into bilateral control systems. Assuming no delay on the master side a master-slave system can be constructed with a centralized controller on master side. Such a bilateral system has delay in the position and force measurement from the slave side to the controller. Using the same idea presented above, predictor given in (23) may be used to estimate position and velocity. However, compensation of delay in force measurement may not be realized using the same structure. The reason is very simple; in estimation of position, known structure of the plant is used and for estimation of force in the same framework, nominal slave environment should be known by the controller. That is unlikely in most of the cases. Having all of this in mind, extension to bilateral control may establish full tracking in position since delay in position loop may be compensated. On the other hand, force tracking on the master side must be established as a separate loop. That would ask for formulation of bilateral control problem as

$$
\begin{aligned}
& e_{x}(t)=x_{m}(t)-\hat{x}_{s}(t), \\
& e_{F}(t)=F_{m}(t)-F_{s}\left(t-\tau_{m}\right) .
\end{aligned}
$$

The structure of such a controller is depicted in Fig. 8 . Selection of control for position and force tracking should follow standard procedure of acceleration control method. In order to avoid loop with delay in force control on the slave side, the force control loop should be closed only on master side. Such a structure will guaranty stability. However, only delayed force can be tracked on the master side

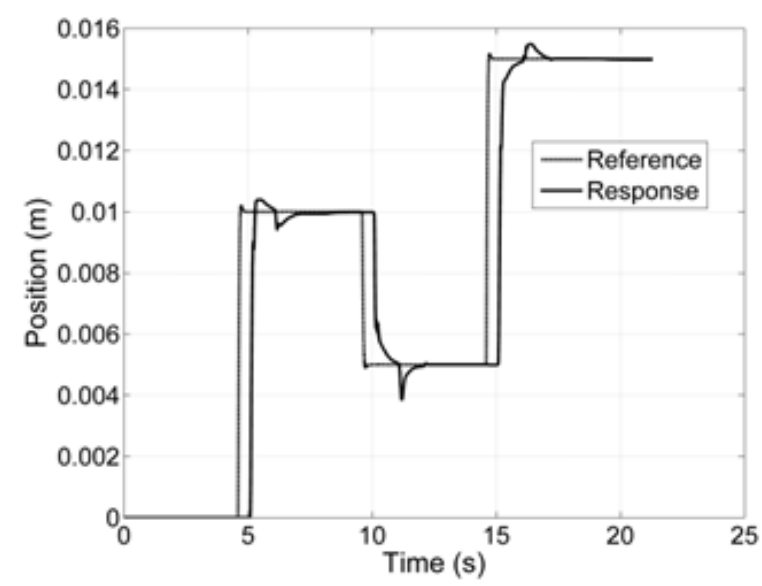

Fig. 5. Step input response - Constant delay: $500 \mathrm{~ms}$, variable delay: $20 \mathrm{~ms}$ 


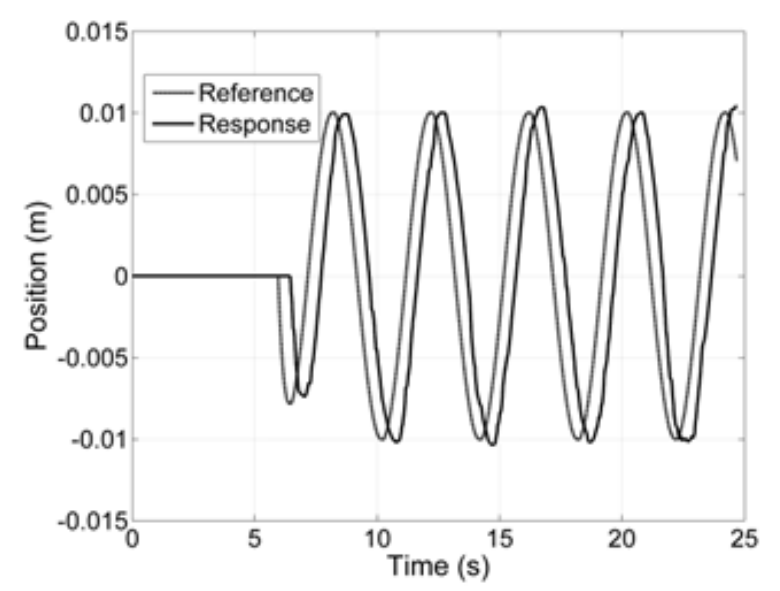

Fig. 6. Sine input response-Constant delay: $500 \mathrm{~ms}$, variable delay: $20 \mathrm{~ms}$

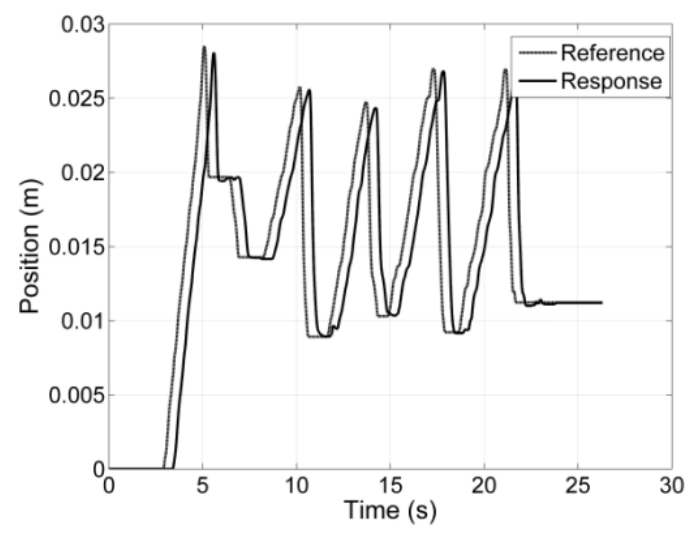

Fig. 7. Random input response - Constant delay: $500 \mathrm{~ms}$, variable delay: $50 \mathrm{~ms}$

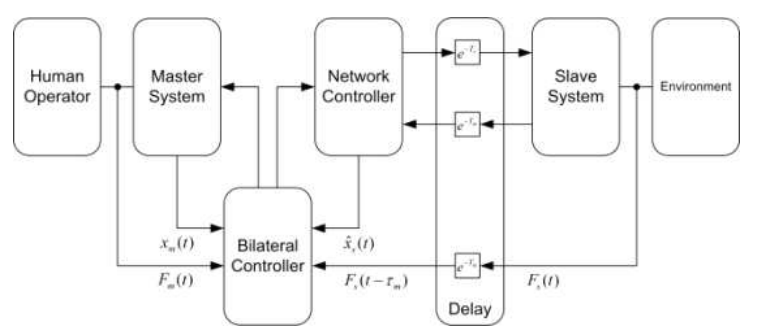

Fig. 8. Block diagram of bilateral system with local force control on master side

which means feeling of touch will be delayed for the loop delay time. To avoid this drawback, additional observers with known environment properties should be employed.

An experimental validation of the above-mentioned bilateral system is given in Fig. 9 with control and mea-
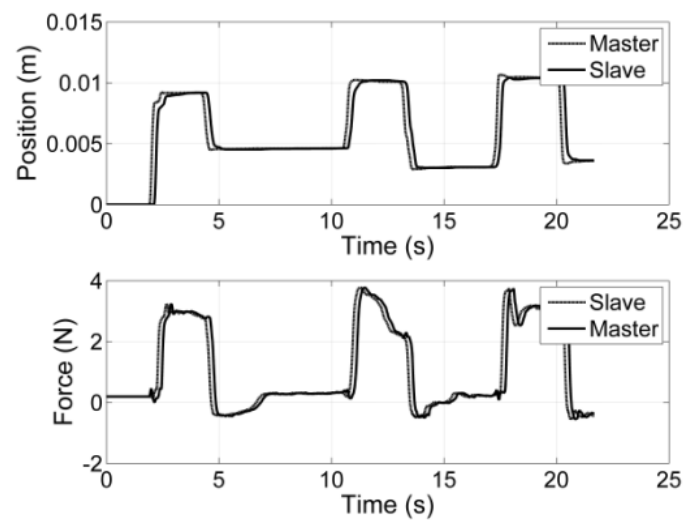

Fig. 9. Position and force response of bilateral system

surement network delays of $200 \mathrm{~ms}$ constant and $20 \mathrm{~ms}$ fluctuating. In that figure, the force on the master side is inverted to lead a better judgment of the effect of measurement delay on the force loop. Actual master force has the symmetric shape of the depicted master force with respect to time axis and hence pushes the force error in (33) to zero. As shown in the first part of Fig. 9, position tracking is achieved although the slave system interacts with the environment.

\section{CONCLUSION}

The control of the system with network delay in the control and measurement channels is discussed and new structure of the communication disturbance observer is proposed. This structure is guarantying the convergence of the estimated output on top of the plant output despite the presence of the time-varying time delay in the loop. The time delay is not required for the proof of the convergence, thus it is not needed to construct the observer. The estimation is provided based only on the available data - the control input and measured plant output subject to the network delay in the measurement channel. Experimental results confirm predicted behavior of the system.

\section{ACKNOWLEDGEMENTS}

This work was supported in part by the TUBITAK 108M520 Project and a Grant-in-Aid for the Global Center of Excellence for High-Level Global Cooperation for Leading-Edge Platform on Access Spaces from the Ministry of Education, Culture, Sport, Science and Technology in Japan.

\section{REFERENCES}

[1] J. Richard, "Time-delay systems: an overview of some recent advances and open problems," Automatica, vol. 39, no. 10, pp. 1667-1694, 2003. 
[2] Z. Palmor, The Control Handbook, ch. Time-Delay Compensation - Smith Predictor and Its Modifications, pp. 224 237. Boca raton, Florida, USA: CRC Press, 1996.

[3] N. Abe and K. Yamanaka, "Smith predictor control and internal model control - a tutorial," in Proceedings of The Society of Instruments and Control Engineers (SICE) 2003 Annual Conference, (Fukui, Japan), pp. 1383-1387, 2003.

[4] V. Utkin, J. Gulgner, and J. Shi, Sliding Mode Control in Electromechanical Systems. Oxon, UK: Taylor \& Francis, 2nd ed., 2009.

[5] G. Leung, B. Francis, and J. Apkarian, "Bilateral controller for teleoperators with time delay via $\mu$-synthesis," IEEE Transactions on Robotics and Automation, vol. 11, no. 1, pp. 105-116, 1995.

[6] R. Oboe and P. Fiorini, "A design and control environment for internet-based telerobotics," International Journal of Robotics Research, vol. 17, no. 4, pp. 433-449, 1998.

[7] Y. Uchimura and T. Yakoh, "Bilateral robot systems on the real time network structure," IEEE Transactions on Industrial Electronics, vol. 51, no. 5, pp. 940-946, 2004.

[8] P. Hokayem and M. Spong, "Bilateral teleoperation: An historical survey," Automatica, vol. 42, no. 12, pp. 20352057, 2006.

[9] R. Anderson and M. Spong, "Bilateral control of teleoperators with time delay," IEEE Transactions on Automatic Control, vol. 34, no. 5, pp. 494-501, 1989.

[10] G. Niemeyer and J. Slotine, "Stable adaptive teleoperation," IEEE Journal of Ocean Engineering, vol. 16, no. 1, pp. 152-162, 1991.

[11] K. Natori, Time Delay Compensation for Motion Control Systems. PhD thesis, Keio University, Yokohama, Japan, 2008.

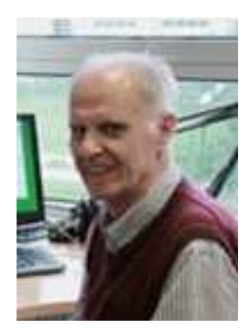

Asif Šabanović received B.S '70, M.S. '75, and Dr. Sci. ' 79 degrees in Electrical Engineering all from University of Sarajevo, Bosnia and Herzegovina. He is with Sabanci University, Istanbul, Turkey. Previously he had been with University of Sarajevo; Visiting Professor at Caltech, USA, Keio University, Japan and Yamaguchi University, Japan and Head of CAD/CAM and Robotics Department at Tubitak - MAM, Turkey. His fields of interest include power elecmechatronics. tronics, sliding mode control, motion control and

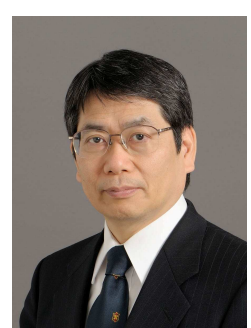

Kouhei Ohnishi got B.E. (1975), M.E.(1977) and Ph.D.(1980) all in electrical engineering from the University of Tokyo. Since 1980, he has been with Keio University and is a Professor in the Department of System Design Engineering. $\mathrm{He}$ is an IEEE Fellow and was serving as President of the IEEE Industrial Electronics Society in 2008 and 2009.

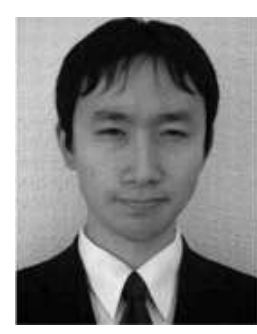

Daisuke Yashiro received the B.E. degree in system design engineering and the M.E. degrees in integrated design engineering from Keio University, Yokohama, Japan, in 2007 and 2009, respectively. From 2009, he is a Research Fellow of the Japan Society for the Promotion of Science (JSPS). His research interests include networked control systems and haptics.

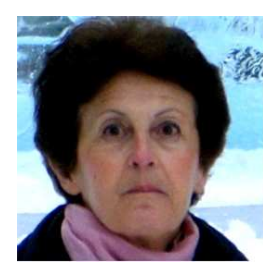

Nadira Šabanović received BSc. in EE from University of Sarajevo, MSc. in EE from Caltech, Pasadena, USA, and $\mathrm{PhD}$ degree from University of Sarajevo. She was with Energoinvest-IRCA in Sarajevo and as a researcher at Caltech, Keio University and Kyushu University. She worked as project specialist at Sabanci University. Her field of interest includes Control systems, Power crosystems assembling and design. electronics, SCADA systems applications, mi-

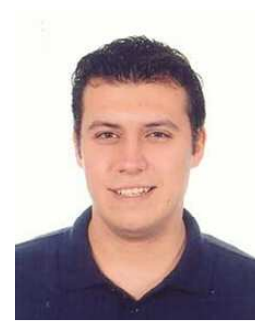

Eray A. Baran received the B.S. degree in Mechatronics Engineering from Sabanci University, Istanbul, Turkey, in 2008. He is currently working toward the M.S. degree in Mechatronics Engineering program of Sabanci University. His research interests include motion control systems, bilateral control and time delayed control systems.

\section{AUTHORS' ADDRESSES}

Prof. Asif Šabanović, Ph.D.

Nadira Šabanović, Ph.D.

Eray A. Baran, B.Sc.E.E.

Faculty of Engineering and Natural Sciences,

Sabanci University,

34956, Istanbul, Turkey

e-mails: asif@sabanciuniv.edu, nadira@sabanciuniv.edu, eraybaran@sabanciuniv.edu

Prof. Kouhei Ohnishi, Ph.D.

Daisuke Yashiro, M.Sc.E.E.

Faculty of Science and Technology,

Keio University,

223-8522, Yokohama, Japan

e-mails: ohnishi@sd.keio.ac.jp, yasshi@sum.sd.keio.ac.jp

Received: 2010-03-05

Accepted: 2010-04-22 